\title{
Regulation of ethylene biosynthesis at the level of 1-aminocyclopropane-1-carboxylate oxidase $(A C O)$ gene
}

\author{
Izabela Ruduś • Magdalena Sasiak • Jan Kępczyński
}

Received: 17 April 2012/Revised: 10 July 2012/Accepted: 30 August 2012/Published online: 18 September 2012

(C) The Author(s) 2012. This article is published with open access at Springerlink.com

\begin{abstract}
Ethylene, a gaseous plant hormone regulates essentially all physiological processes during the plant's life cycle. The practical implications of ethylene biosynthesis regulation for plant improvement have supported the continuous basic research on dissecting the structure of genes encoding ethylene biosynthetic enzymes, their differential expression patterns, and mechanisms underlying their transcriptional activity. ACC oxidase (ACO) is involved in the final step of ethylene production in plant tissues. In various plants several ACO isoforms have been isolated which are encoded by a multigenic family. There is a strong evidence that $A C O$ gene expression is positively correlated to the ethylene production rates and its multiple isoforms are under development and environmental control. Thus, the regulation of $A C O$ gene activity may act either as an additional or in several cases also as a main level for controlling ethylene biosynthesis in higher plants. This review summarizes in detail the knowledge about organization and gene structure, and transcriptional expression of $A C O$ genes from different plant species. The perspectives of manipulating $A C O$ gene as a method in
\end{abstract}

Communicated by A. K. Kononowicz.

Electronic supplementary material The online version of this article (doi:10.1007/s11738-012-1096-6) contains supplementary material, which is available to authorized users.

I. Ruduś · J. Kępczyński ( $₫)$

Department of Plant Physiology and Genetic Engineering, Szczecin University, ul. Wąska 13, 71-415 Szczecin, Poland e-mail: jankepcz@wp.pl

M. Sasiak

Medical Diagnostic Laboratory, The Regional Specialist

Hospital, ul. Hubalczyków 1, 76-200 Słupsk, Poland biotechnological modification of ethylene synthesis are also discussed.

Keywords Ethylene biosynthesis - ACC oxidase - Gene structure $\cdot$ Gene expression - Genetic transformation

\section{Ethylene: a unique plant hormone}

Ethylene, the simplest unsaturated hydrocarbon (two carbons with a double bond) is a gaseous plant hormone which regulates essentially all physiological processes during the plant's life cycle. It is responsible for signaling changes in: seed dormancy and germination, root growth and nodulation, shoot and leaf formation, flower and fruit development, different organs senescence and abscission, plant defense mechanisms, and a number of interactions with other plant hormones (Kępczyński and Kępczyńska 1997; Wang et al. 2002; Chaves and Mello-Farias 2006). Although, ethylene is undoubtedly essential for proper plant growth, development, and survival, it may also be deleterious to plants in some instances. Increased ethylene levels in plants exposed to various types of stress including chilling, heat, nutrient deprivation, anaerobiosis, wounding, and pathogen infection with increased damage to plant growth and health as the result has been reported (Stearns and Glick 2003). There is considerable commercial interest in modifying the amount of ethylene produced under ripening, senescing or stress conditions and thereby creating plants with more robust and/or desirable traits (Kępczyński and Kępczyńska 2005; Handa et al. 2010). The practical implications of ethylene biosynthesis regulation for plant improvement have supported the continuous basic research on dissecting the structure of genes encoding ethylene 
biosynthetic enzymes, their differential expression patterns and mechanisms underlying their transcriptional activity.

Ethylene biosynthesis begins from $S$-adenosylmethionine (SAM) and includes two key steps (Fig. 1) as reviewed by Yang and Hoffman (1984) and more recently by Pech et al. (2010). First, 1-aminocyclopropane-1-carboxylate synthase (ACS) [EC 4.4.1.14] catalyses the cyclization of SAM to 1-aminocyclopropane-1-carboxylic acid (ACC), which is often considered the rate-limiting reaction in the pathway. ACS also produces $5^{\prime}$-methylthioadenosine (MTA) which is recycled to regenerate methionine. The final step, oxygendependent conversion of ACC to ethylene, is catalyzed by ACC oxidase (ACO) [EC 1.14.17.4]. ACC is converted to ethylene by a modification of carbons C-2 and C-3 of ACC, while $\mathrm{C}-1$ is converted to cyanide and the carboxyl group converted into carbon dioxide.

In this study, we have focused on a specific involvement of $A C O$ genes in the regulation of ethylene synthesis. We aimed to give a comprehensive and up-to-date coverage on their structure, patterns of expression and some regulatory mechanisms underlying their transcriptional activity. We have also discussed the possibilities of exploiting $A C O$ genes in manipulating the level of ethylene production and subsequently controlling plant performance.

\section{Characterization of ACO enzyme}

ACC oxidase is a member of ferrous-dependent nonheme oxygenases, most of which utilize 2-oxoglutarate (2OG) as a co-substrate (Mirica and Klinman 2008). In its sequence, two distinct domains can be distinguished; an N-terminally located highly conservative non-heme dioxygenase DIOX_N region and a C-terminally located 2OG-FeII_Oxy region (Fig. 2; Punta et al. 2012). The Fe2OG dioxygenases catalyze a variety of two-electron oxidations including hydroxylations, desaturations, and oxidative ring closures (Costas et al. 2004). Although the sequence homology among these enzymes is not high, all their active sites contain a single ferrous ion bound in a tridentate ligand arrangement referred to as a "2-His-1-carboxylate facial triad" (Mirica and Klinman 2008). Studies by Yoo et al. (2006) revealed that the positive-charged surface in the C-terminal helix of the ACO, spanning the exclusively conserved motif (Lys296-Glu301), could be a major stabilizer in the spatial arrangement of reactants and that the positive-charge network between the active site and C-terminus is critical for ACO activity.

Although numerous attempts were made to isolate the ACO, it was not purified to homogeneity because of its low abundance until molecular cloning and heterologous expression were employed as reviewed by Alexander and Grierson (2002). ACO can be eluted as a single, active, hydrophobic protein with molecular mass of about 35-40 kDa after partial purification, which correlates with the length of its polypeptide (about 300-330 AA) and known mRNA sequences with coding sequence in the range of $918-1,002 \mathrm{bp}$.

The subcellular localization of ACO is still under debate. The lack of a signal peptide classically required for the protein to cross the plasma membrane suggested a cytosolic targeting for ACO (Pech et al. 2010). However, the subcellular localization of ACO is still not clearly defined. Some experiments showed that, in tomato and apple fruit, it is mainly located in the apoplast (Ramassamy et al. 1998) whereas other immunolocalization studies indicated the cytosol as ACO final localization (Chung et al. 2002).

\section{Structure of $A C O$ gene}

ACO is encoded by a small multigene family comprised usually of three to four members (Pech et al. 2010; Table $\mathrm{S} 1)$. The most numerous $A C O$ gene family has been identified in Populus trichocarpa in which genome seven homologs are present. There are many instances that only one $A C O$ gene is known for a certain species so far, however, further studies should inevitably lead to the discovery of some other homologs.

The common $A C O$ gene structure in many different plant species consists of four exons interspersed by three introns (Fig. 3a). The occurrence of such organization has been observed in over $80 \%$ of genes with known sequence of their genomic DNA (Table S1). The coding sequence is divided unequally in exons: the first $\sim 100 \mathrm{bp}$ are located in exon 1 downstream of UTR5' of varying length, the next $\sim 200$ and $\sim 300$ bp in exon 2 and 3, respectively. The last
Fig. 1 The key enzymes of ethylene biosynthetic pathway. ACC 1-aminocyclopropane-1carboxylic acid, ATP adenosine triphosphate, $H C N$ hydrogen cyanide, $S A M$ $S$-adenosylmethionine (Yang and Hoffman 1984)
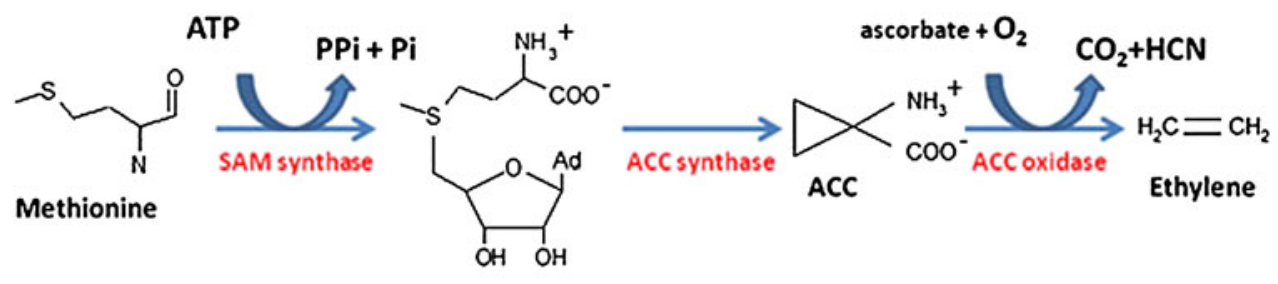


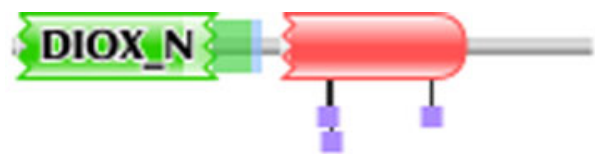

Fig. 2 An exemplary domain organization of ACO (AT-ACCO4) polypeptide with DIOX_N (green box) and 2OG-FeII_Oxy (red box) architecture. Pfam-predicted active sites, residues which are directly involved in catalysis of a reaction, for ACO-three iron binding residues (H, D, H) are visualized as lollipops (Punta et al. 2012) (color figure online)

section of CDS, also nearly $300 \mathrm{bp}$, together with UTR $3^{\prime}$ region comprises exon 4 . The lengths of first three sections of $A C O$ CDS are rather uniform among different species, the forth one is more variable ranging from $232 \mathrm{bp}$ in $A T$ $A C O 5$ to $327 \mathrm{bp}$ in $M D-A C O 2$. The common structure composed of four exons, however, is not always preserved among all members of the gene family in certain species. There are some exceptions to this rule, in which $A C O$ genes are composed of only three exons interrupted by two introns. Such condensed structure was found, for instance, in two members of melon gene family $(C M-A C O 2,3)$ (Lasserre et al. 1996), one gene from peach (PP-ACO2) (Ruperti et al. 2001) and also in Arabidopsis thaliana ATACO1, Dianthus caryophyllus DC-ACO, Musa acuminata MA-ACO3, Pinus taeda PT-ACO3, Zea mays ZM-ACO35 (Fig. 3b, c). If we could consider the presence of four exons as a primary feature, the deletion of either third or second intron might have led to the derivative structures composed of only three exons with distinctive CDS length extension in subsequent last or middle exon, respectively.

A phylogenetic tree constructed on the basis of ACO amino acid sequences from different seed plant species (gymnosperms, dicots, monocots) illustrates general homology of ACO isoforms (Fig. 4). There is a clear distinction between ACO enzymes and other 2-oxoglutarate dioxygenases which constitute separate divisions. The
ACO division can be further divided into two main subdivisions, each comprising several groups and subgroups with the sequences from phylogenetically distant species. The homology analysis reveals that the ACO sequence evolution most probably started with a gene duplication which should have taken place at least before the divergence of monocotyledonous and dicotyledonous species. Several further duplication events together with the speciation processes comprising the accumulation of mutations, created multigenic families of paralogs present in most if not all contemporary seed plants. It is also quite evident that deletions leading to the change in gene structure from four-exonic to three-exinic must have occurred independently several times during speciation.

\section{Solanaceae}

Two species of Solanaceae family, Lycopersicon esculentum and Petunia hybrida, were objects of the pioneering experimental works concerning ACO, better known at that time as the ethylene forming enzyme (EFE). So it is not surprising that their $A C O$ genes are often exploited as references for new isolated orthologs. One of the best characterized $A C O$ gene families is from $L$. esculentum (tomato). It is one of the largest, comprising five different paralogs: LE-ACO1 (Köck et al. 1991), LE-ACO2 (Holdsworth et al. 1987), LE-ACO3 (Barry et al. 1996), LE-ACO4 (Nakatsuka et al. 1998), LE-ACO5 (Sell and Hehl 2005). The coding regions of $L E-A C O 1, L E-A C O 2$, and $L E-A C O 3$ are interrupted by three introns. $L E-A C O 1$ and $L E-A C O 3$ display the highest nucleotide identity $(99 \%)$ in exon 3 , while $L E-A C O 2$ has lower degree of conservation to these two genes (Barry et al. 1996). Amino acid analysis shows that $L E-A C O 5$ has the highest homology with $L E-A C O 4$ (Sell and Hehl 2005). However, the tomato ACO genes have unique $5^{\prime}$ - and $3^{\prime}$-untranslated regions. It was used to
Fig. 3 A schematic presentation of different $A C O$ gene structures. The most common structure composed of four exons (a). Alternative structures comprising three exons $(\mathbf{b}, \mathbf{c})$. Denotations: exons are filled blocks, white UTR regions, gray coding sequences; bold lines are introns. ${ }^{1}$ median value of CDS length; ${ }^{2}$ mean value of CDS length. AT, Arabidopsis thaliana; CM, Cucumis melo; DC, Dianthus caryophyllus; MA, Musa acuminate; $\mathrm{PP}$, Prunus persica; PT, Pinus taeda; ZM, Zea mays

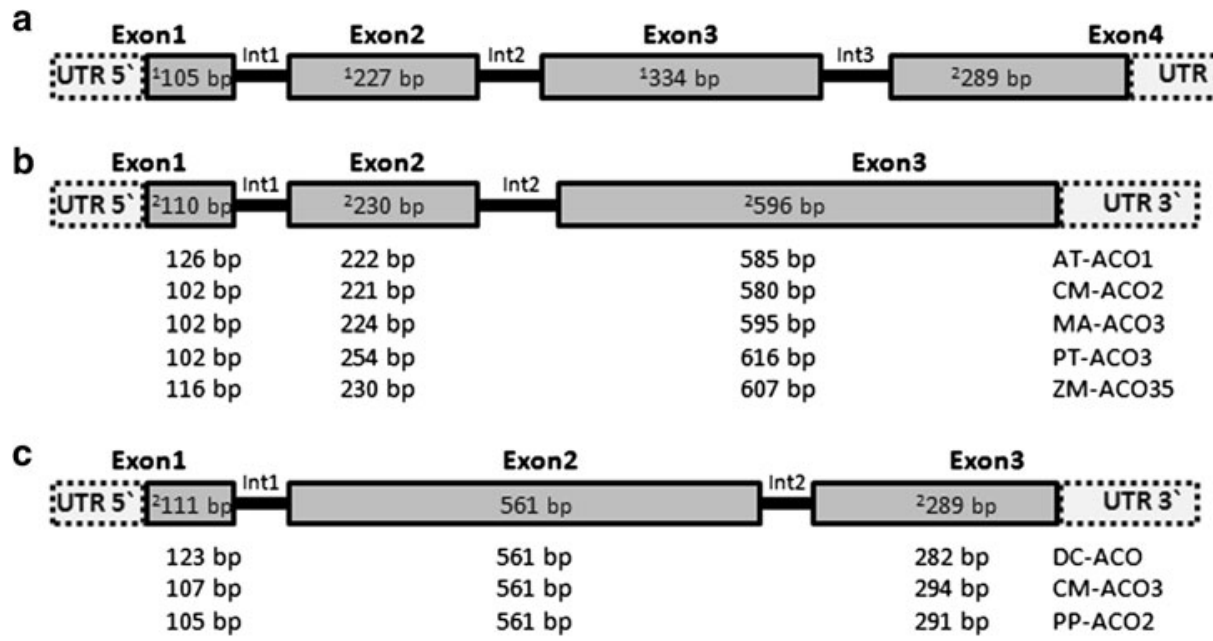




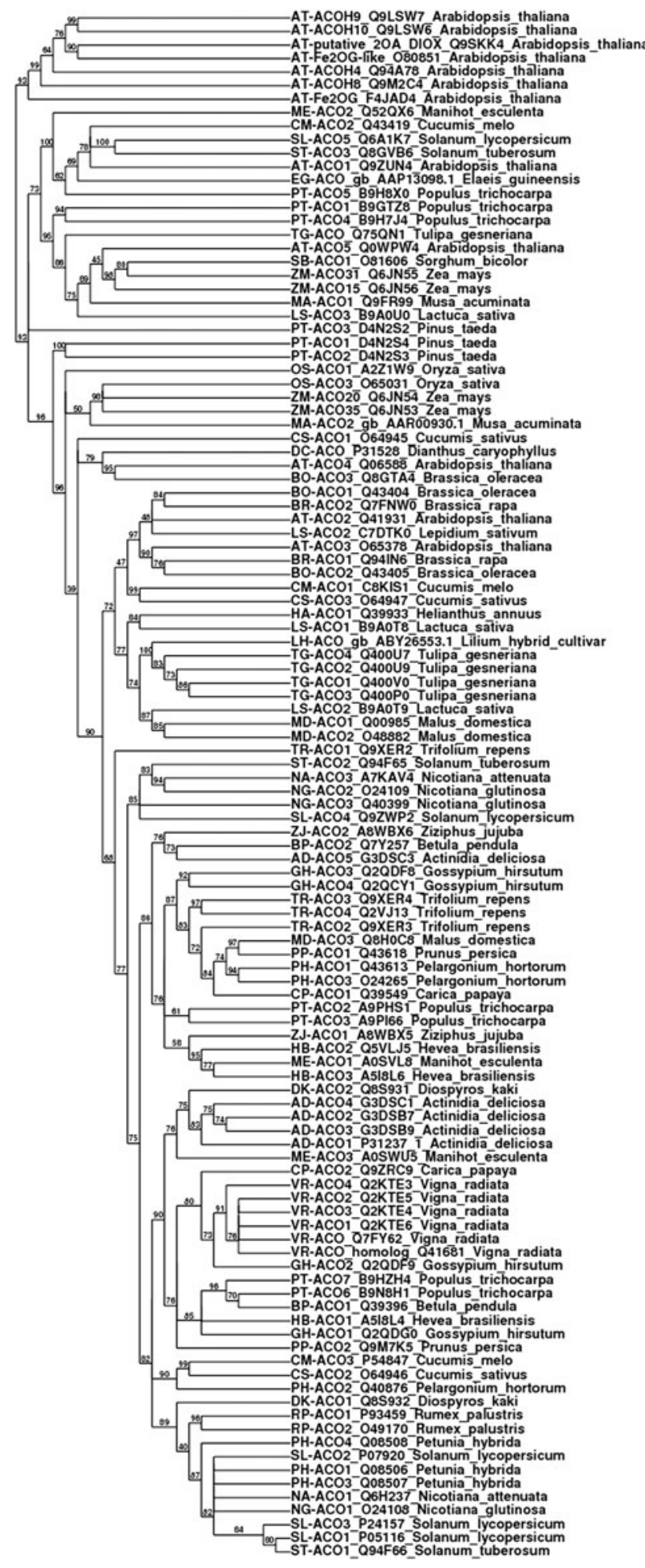

analyze gene-specific $A C O$ expression in various tissues at different stages of plant development (Barry et al. 1996). All of the tomato $A C O$ genes are transcriptionally active.

Also in $P$. hybrida $A C O$ genes comprise a multigene family of four genes $\mathrm{PH}-\mathrm{ACO}$, $\mathrm{PH}-\mathrm{ACO}$, $\mathrm{PH}-\mathrm{ACO}$, and PH-ACO4 (Tang et al. 1993; Table S1). These genes were
4Fig. 4 Phylogenetic tree constructed from a multiple alignment of ACO full amino acid sequences from different species obtained from UniProt or NCBI databases. The analysis was performed on the Phylogeny.fr platform (Dereeper et al. 2008) and comprised the following steps: input sequences alignment with MUSCLE (v3.7) configured for highest accuracy (MUSCLE with default settings); curation of ambiguous regions with Gblocks (v0.91b) (parameters: minimum length of a block after gap cleaning: 10, no gap positions allowed in the final alignment, all segments with contiguous nonconserved positions bigger than eight rejected, minimum number of sequences for a flank position: $85 \%$ ); construction of the phylogenetic tree using the maximum likelihood method implemented in the PhyML program (v3.0 aLRT); graphical representation and edition of the phylogenetic tree with TreeDyn (v198.3)

identified in two tandemly arranged regions. The first region contains $\mathrm{PH}-\mathrm{ACOl}$ gene and a pseudogene $\mathrm{PH}$ $A C O 2$, which are separated from each other by a $1.2-\mathrm{kb}$ intergenic region. The genes $\mathrm{PH}-\mathrm{ACO} 3$ and $\mathrm{PH}-\mathrm{ACO} 4$ are a part of the second region. In contrast, these two tandem genes are separated by a longer, $6 \mathrm{~kb}$ sequence (Tang et al. 1993). The structural organization of all of the characterized petunia $A C O$ genes is identical to that observed in tomato genes (Barry et al. 1996). There are four coding regions interrupted by three introns. The proteins encoded by $A C O$ genes share more than $90 \%$ identity with one another and more than $70 \%$ identity with ACOs from other plant species. However, the highest homology in introns and $3^{\prime}$-untranslated region was noticed only between $\mathrm{PH}-\mathrm{ACO}$ and $\mathrm{PH}-\mathrm{ACO}$. The studies have indicated that three members of petunia $A C O$ gene family are transcriptionally active- $P H-A C O 1,3,4$ (Tang et al. 1993). The fourth $\mathrm{PH}-\mathrm{ACO} 2$ is postulated to be a pseudogene as it is characterized by specific features-a conversion of $\mathrm{G}$ to $\mathrm{T}$ disrupting the translation initiation codon and a $2 \mathrm{bp}$ deletion at the beginning of the second exon disrupting the reading frame of this mRNA.

\section{Brassicaceae}

The family includes many economically important edible and industrial oilseed, vegetable, condiment, and fodder crop, such as Brassica oleracea (broccoli, cabbage, and cauliflower), Brassica rapa (turnip, Chinese cabbage), Brassica napus (rapeseed), or Sinapis alba (white mustard). It also includes the model organism A. thaliana that has revolutionized our knowledge in almost every field of modern plant biology.

In the Arabidopsis genome, six genes coding for ACOs were identified in silico by Babula et al. (2006). Until now, only EAT1 (AT-ACO4) and AT-ACO2 gene structures, gene expression patterns and protein activities have been investigated (Gómez-Lim et al. 1993; Raz and Ecker 1999; Ramonell et al. 2002; Raghavan et al. 2006; Linkies et al. 2009). However, based on the data from the UniProt database, there is substantial transcriptional evidence for 
three more $A C O$ paralogs $(A T-A C O 1,3,5)$. A query in TAIR database for genes with 1-aminocyclopropane-1carboxylate oxidase activity resulted in 13 loci (Table S1), some of them representing putative ACOs or putative 2OG dioxygenases. The homology analysis between these available $A$. thaliana $A C O$ coding sequences allows for a strict distinction of five $A T-A C O$ genes from their homologs or putative dioxygenases (Fig. 4; Table S1). It is interesting that four out of five $A T-A C O$ genes are located on the same chromosome 1 and have a common structure (four exons interspersed by three introns) with $A C O s$ from other species. The exception is $A T-A C O 1$ located on chromosome 2 , which has only three exons similarly to all Arabidopsis putative dioxygenase genes.

\section{Poaceae}

Monocotyledonous plants are less studied in respect to $A C O$ gene structural and functional analysis. Still, there are several grass species for which ACO genes were isolated and characterized (Table S1).

Although browsing Rice Genome Annotation Project for $A C O$ genes has resulted in 23 relevant loci, there are only three paralogs of $A C O$ gene in rice isolated and characterized so far with distinct annotations in GenBank database (Table S1; Ouyang et al. 2007). The first, OS-ACO1, was isolated by Mekhedov and Kende (1996). Two others, $O S-A C O 2$ and $O S-A C O 3$, were characterized by Chae et al. (2000). The overall nucleotide sequence homology between $O S-A C O 2$ and $O S-A C O 3$ was reported as $72.6 \%$. The coding regions of $O S-A C O 2$ and $O S-A C O 3$ share 92 and $72 \%$ sequence identity at the amino acid level with $O S$-ACO1, indicating that the $O S-A C O 3$ gene is a more divergent member of the gene family. In contrast to $A C O$ genes from other species, most $O S$-ACOs predicted in rice genome, do not show the typical four exon structure (Ouyang et al. 2007).

Gallie and Young (2004) revealed that ACO gene family in maize is represented by four genes, designated $Z M$ ACO15, ZM-ACO20, ZM-ACO31, and ZM-ACO35, which can be grouped into two subfamilies. One of them comprises ZM-ACO2O and ZM-ACO35 which are highly similar in amino acid sequence (91\% amino acid identity) and in the number and position of their introns. The other subfamily consists of ZM-ACO15 and ZM-ACO31 which are also highly similar to each other (96\% amino acid identity). These two subfamilies have diverged considerably so that a greater degree of divergence is found among members of the maize $A C O$ gene family than that reported for other species such as petunia and tomato (Tang et al. 1993; Barry et al. 1996). ZM-ACO15 and ZM-ACO31 are more similar to ACOs from Arabidopsis and rice than they are to $Z M-A C O 20$ and $Z M-A C O 35$, suggesting that gene duplication and divergence of the two subfamilies, occurred prior to the divergence of monocotyledonous and dicotyledonous species. ZM-ACO20 possesses all twelve amino acid residues that are conserved among iron- and ascorbate-dependent dioxygenases, whereas ZM-ACO35, $\mathrm{ZM}-\mathrm{ACO} 15$, and $\mathrm{ZM}-\mathrm{ACO} 31$ contain most but not all of the conserved residues.

\section{Pinaceae}

In comparison to other higher plants, either dicots or monocots, our knowledge of $A C O$ genes in Gymnospermae is rather limited. Quite recently an $A C O$ gene family in loblolly pine comprising five paralogs $P T$-ACO1, $P T$ ACO2, PT-ACO3, PT-ACO4, and PT-ACO5 has been characterized (Yuan et al. 2010). Alignment of the deduced PT-ACO1 amino acid sequence with the sequences from other plant ACOs showed the encoded protein to contain all the conserved residues characteristic of ACOs. $P T$ $A C O 2$ gene showed $98 \%$ identity to $P T-A C O 1$ in the nucleotide coding sequence, leading to its classification as a "nearly identical paralog" (NIP) which is a very unique feature among $A C O$ genes. In contrast, $P T$-ACO3 has shown to be quite divergent from the first two paralogs in overall gene structure in containing only two introns instead of three.

\section{Expression activity of $A C O$ genes}

Typically in higher plants, ethylene production is regulated by both developmental and external signals. During plant development, higher rates of ethylene evolution occur from young (vegetative, floral, and fruit) tissues that display a high rate of cell division. During the subsequent cell expansion and elongation stages, ethylene production declines. Finally it increases during fruit ripening, and leaf and floral senescence (Wang et al. 2002).

The $A C O$ genes appear to be expressed in all vegetative (leaves, root, and epicotyl) and reproductive (flower and fruit) plant tissues and originally they were thought to be expressed constitutively. Later studies, however, revealed that there are differences in accumulation of specific $A C O$ transcripts observed in various physiological processes. This suggests a different role played by $A C O$ homologs during different developmental stages. The conversion of ACC into ethylene by ACO enzyme well coincides with the site of ethylene evolution so the determination of $A C O$ transcript abundance may serve as an ethylene biosynthesis indicator.

For example, the ST-ACO1 and ST-ACO2 genes of potato are strongly expressed in leaves, but their expression in roots and tubers remains at low levels (Nie et al. 2002). In apple (Malus domestica cv. Royal Gala), three identified 
isoforms of $A C O$ gene are differently expressed in fruit and leaf tissues (Binnie and McManus 2009). MD-ACO1 is restricted to fruit tissues, with optimal expression in ripening fruit, $M D-A C O 2$ expression occurs more predominantly in younger fruit tissue, with some expression in young leaf tissue, while $M D-A C O 3$ is expressed predominantly in young and mature leaf tissue, with less expression in young fruit tissue and least expression in ripening fruit. Also Momonoi et al. (2007) observed a differential regulation of five $A C O$ paralogs in tulip among the vegetative tissues and during flower senescence.

\section{Seed dormancy and germination}

Ethylene is implicated in the seed formation and germination of many plant species (reviewed by Kępczyński and Kępczyńska 1997; Matilla and Matilla-Vázquez 2008; Linkies and Leubner-Metzger 2012).

Not much is known about $A C O$ expressional activity throughout zygotic embryogenesis, a morphogenetic program which proceeds seed maturation. Rodríguez-Gacio et al. (2004) reported that one of $A C O$ homologs, $B R$ $A C O 1$ is highly expressed during the first phases of zygotic embryo formation in Brassica rapa, to decline afterwards and become undetectable during desiccation. It has been suggested that the maximum ethylene synthesis found at the beginning of embryogenesis is dependent on $A C O$ expression and activity. On the other hand, in Sysimbrium seeds, SO-ACO2 transcripts rose during embryo development and further increased with the seed desiccation (Iglesias-Fernández and Matilla 2009).

In some species, endosperm undergoes programmed cell death late in its development which onset is also known to be under control of ethylene. Such a situation appears during seed development in cereals. In maize kernel, $A C O$ genes are nearly exclusively expressed in the endosperm, and $Z M-A C O 2 O$ is largely responsible for this transcript accumulation (Gallie and Young 2004). Expression of $A C O$ genes during late endosperm development is likely to occur in those regions of the endosperm that remain viable at this stage, e.g., the subaleurone, aleurone, or pedicelproximal starchy endosperm. The $A C O$ gene family, and $Z M-A C O 20$ in particular, represents the only component of the ethylene biosynthetic and perception machinery examined whose expression increases during late endosperm development, perhaps to insure continued ethylene production in those regions of the endosperm that remain alive during this period.

The seeds of most angiosperms are dormant at maturity (Matilla and Matilla-Vázquez 2008). Seed dormancy is developed during the last period of embryogenesis and prevents germination under unfavorable conditions. It has been proposed that ethylene may contribute to the breaking of dormancy in some species but its involvement in the removal of dormancy is still debated, especially in relation to ethylene-GA synergism (Kępczyński and Kępczyńska 1997; Matilla and Matilla-Vázquez 2008). It was proposed for example that transcriptional regulation of the FS-ACOI gene plays a major role in regulating ethylene production required to break dormancy in beechnuts (Calvo et al. 2004).

Seed germination starts with imbibition of a dry seed and is considered as completed with the emergence of the radicle. Accumulation of ACOs and increased ethylene evolution accompany seed germination in several species (Munoz de Rueda et al. 1995; Petruzzelli et al. 2000; Hermann et al. 2007; Linkies et al. 2009; Iglesias-Fernández and Matilla 2010). In many instances it is ACO that controls the ethylene evolution during seed germination. As shown in pea seeds, ethylene may regulate its own biosynthesis through a positive feedback loop that enhances ACO expression (Petruzzelli et al. 2000). Though, in contrast with pea seeds, no such autocatalytic enhancement was observed for $A C O$ in germinating sugar beet (Hermann et al. 2007), or the ACO2 orthologs of Sysimbrium officinale (Iglesias-Fernández and Matilla 2009) and Lepidium (Linkies et al. 2009). The levels of $A C O$ transcripts have been shown to be regulated not only by ethylene itself but also other phytohormones (Lin et al. 2009). It is evident that during seed germination upon hormone treatment (ABA or GA) of A. thaliana, the regulation of ethylene synthesis is mediated by ACO (Linkies and Leubner-Metzger 2012).

Rodríguez-Gacio et al. (2004) observed that the transcription of the $B R-A C O 1$ gene throughout the germination process of turnip tops remains at a low level during the imbibition phase, however, the transcript accumulation increases during embryonic axis protrusion and occurs predominantly in the growing organs of the seed (embryonic axis and radicle), being scarce in cotyledons. Similarly, PS-ACO1 mRNA, ACO activity, and ethylene production were almost exclusively detected in the embryonic axis of germinating pea seeds (Petruzzelli et al. 2000). It is postulated that in the embryonic axis, ethylene could act by promoting radial cell expansion or by decreasing the seed base water potential (Linkies and Leubner-Metzger 2012).

In seeds, where endosperm acts as a mechanical barrier, its weakening is essential for the radical protrusion. It was shown that ethylene, counteracting the inhibitory action of abscisic acid (ABA), promotes endosperm cap weakening and endosperm rapture (Linkies et al. 2009). Prior to the onset of endosperm rapture, there has been an accumulation of $\mathrm{ACO} 2$ transcripts observed (Iglesias-Fernández and Matilla 2009; Linkies et al. 2009). The collective evidence from three different species of Brassicaceae suggests that $A C O 2$ orthologs may play a key regulatory role in this specific step of seed germination. 
Vegetative phase of development

The vegetative development of plants is strongly dependent on the action of ethylene which has a close and reciprocal relation with auxin, another major determinant of plant architecture (Vandenbussche et al. 2012). During vegetative development, differential $A C O$ gene expression has been observed in mung bean (Kim and Yang 1994), tomato (Barry et al. 1996; Moeder et al. 2002), sunflower (Liu et al. 1997), potato (Nie et al. 2002), and tulip (Momonoi et al. 2007) tissues.

It is generally accepted that all plant organs are capable of synthesizing ethylene from ACC, however, some data clearly imply that the contribution of different cell types within an organ or tissue is not equal (Vandenbussche et al. 2012). In the root of Arabidopsis for example, at least one member of the $A C S$ family is expressed in each cell type, whereas the expression of the known $A C O$ genes does not cover all root cell types (Dugardeyn et al. 2008; Vandenbussche et al. 2012). Similarly, ZM-ACO expression was restricted to the root cap, protophloem, and the companion cells associated with metaphloem sieve elements (Gallie et al. 2009). Such a differential expression pattern highly probably reflects variable enzymatic activity and may indicate the exact ethylene production site which cannot be assessed using currently available analytical methods.

Ethylene exerts multiple effects on plants during the vegetative stage of development (Vandenbussche et al. 2012). In general, primary and lateral root elongation is inhibited, whereas root hair development is stimulated. By contrast in hypocotyls of light-grown seedlings, as in stems of some semi-aquatic species, and during shade avoidance, ethylene can stimulate elongation. Leaf emergence is enhanced by ethylene, leaf expansion, however, is mostly inhibited. It is also known that keeping ethylene levels low during vegetative development is important in order to allow an optimal expansion of the root and the shoot, which can be achieved through negative feedback regulation of ethylene biosynthesis genes. Despite this, and the fact that there are specific spatial and temporal expression patterns of $A C O$ genes in vegetative tissues, the exact role of $A C O$ as a possible regulatory point in ethylene production still needs to be elucidated.

There are some examples of direct evidence for $A C O$ involvement in the regulation of ethylene biosynthesis. An expression study in white clover indicated that $A C O$ plays a regulatory role in leaf ontogeny (Hunter et al. 1999). In the apical hook of $A$. thaliana, AT-ACO2 expression is positively regulated by ethylene and restricted to the time period that the cells are ethylene sensitive (Raz and Ecker 1999). The $A T-A C O 2$ transcripts have exhibited differential localization in the hook, accumulating in its outer cells. Auxin antagonists promoted primary root elongation, simultaneously reducing root diameter and root hair development in Linum usitatissimum affecting the expression of ethylene biosynthesis genes, both $A C S$ and $A C O$ transcripts levels were inhibited (Zhao and Hasenstein 2009). However, Takahashi et al. (2010) observed that among the differentially regulated $A C O$ genes, $L S$-ACO2 plays a key role in ethylene production during low-pHinduced root hair formation in lettuce. A predominant $A C O$ gene, $O S$ - $A C O 1$, has been isolated from submerged internodes of deepwater rice, and its high transcript levels are associated with internode elongation during submergence (Mekhedov and Kende 1996) and also at the heading stage (Iwamoto et al. 2010). OS-ACO1 gene expression remains under phytochrome control, especially phytochromes A and B (Iwamoto et al. 2011).

\section{Generative phase of development}

The studies in ornamental plants, have shown that flower opening, pollination, petal senescence, and abscission are often associated with transcriptional regulation of the $A C S$ and $A C O$ genes which in turn control ethylene synthesis (Bui and O’Neill 1998; Jones 2003; Fernández-Otero et al. 2006; Roeder et al. 2009). Trivellini et al. (2011) concluded that at the early flower development stage of Hibiscus rosa-sinensis, both ACS and ACO genes are likely to be involved in the regulation of ethylene biosynthesis transcriptionally, but during flower senescence, ethylene biosynthesis is regulated at $A C O$ levels solely. Also in Alstroemeria, ethylene synthesis is regulated through $A C O$ gene expression, rather than $A C S$, at the last stages of development (Wagstaff et al. 2005). Different isoforms of $A C O$ gene are also involved in ethylene production during fruit development and ripening as shown in melon (Lasserre et al. 1996), tomato (Barry et al. 1996), peach (Mathooko et al. 2004), Coffea arabica (Pereira et al. 2005), Ficus carica (Owino et al. 2006), and banana (Choudhury et al. 2008a, b).

It is widely accepted that ethylene biosynthesis in ripening fruits and senescing flowers is subject to both positive and negative feedback regulation (Kende 1993). A positive feedback regulation, through an increase in ethylene production triggered by exogenous ethylene, with the activation of $A C S$ and/or $A C O$ has been reported for petunia (Tang and Woodson 1996), carnation (Jones and Woodson 1997), and orchid (O’Neill et al. 1993). A negative feedback regulation has been shown for transgenic petunia flowers (Wilkinson et al. 1997) and ripening tomato and banana (Nakatsuka et al. 1998; Inaba et al. 2007). However, Trivellini et al. (2011) have shown that ethylene biosynthesis can be under both positive and negative feedback regulatory mechanisms in a tissue-temporal-specific manner during flower development and 
senescence depending on differential expression of $A C S$ and $A C O$ genes. Similarly, the studies in tomato and banana have shown a differential feedback regulation of ethylene biosynthesis enzymes between pre-climacteric and ripening fruits and also between different tissues (Nakatsuka et al. 1998; Inaba et al. 2007).

\section{Stress responses}

Autocatalytic or feed-forward effects on ethylene production are associated not only with developmental cues, such as seed germination, ripening, shedding, wilting, and senescence, but also are observed in stress situations (Linkies and Leubner-Metzger 2012; Vandenbussche et al. 2012). Substantial evidence implies that these effects can be achieved through the elevation of transcript levels of key biosynthetic enzymes. The expression of genes encoding ACOs differs not only with tissue, stage of development but also with environmental conditions. Studies concerning different abiotic (temperature, wounding, and flooding) and biotic (pathological infection) treatments showed many instances of $A C O$ gene differential upregulation. It was proposed that a biphasic mode of $A C O$ transcript accumulation, similar to $A C S$ may be a feature of stress-induced ethylene synthesis in tomato (Moeder et al. 2002). In potato, highly increased expression of all $A C O$ genes, in both low and high temperature was observed (Nie et al. 2002). Wounding stimulated principally the transcription of some $A C O$ paralogs: $S T$-ACO1 (Nie et al. 2002), NG-ACO3 (Kim et al. 1998), PP-ACO1 (Ruperti et al. 2001), MA-ACO1 (Pan and Lou 2008). In contrast, Choudhury et al. (2008b) observed that in preclimacteric banana fruit, wounding down-regulated the expression of both $M A-A C S 1$ and $M A-A C O 1$ genes and thus inhibited ethylene production.

The effect of flooding in potato induced the expression of ST-ACO1 and ST-ACO2; nevertheless ST-ACO1 appeared to be more sensitive to this stress. Other reports showed that also expression of $R P-A C O 1$ responded to these conditions (Vriezen et al. 1999). In many species, including maize, the root undergoes re-modeling in response to low oxygen that occurs during flooding through the selective death of cortical cells which generates aerenchyma (Evans 2003). Hypoxia-induced cortical cell death is mediated by ethylene and is accompanied by increases in $A C S$ and $A C O$ expression in several species (Wang and Arteca 1992; Zhou et al. 2001; Gallie et al. 2009). The cell death induced by hypoxia is specific to the cortex, suggesting differential expression of the ethylene biosynthetic machinery in the cortex or sensitivity of this cell type to ethylene.

Just like the abiotic stresses, biotic treatments played the crucial role in synthesis of ACOs. The virus invasion is correlated with higher ethylene synthesis; it is suggesting that $A C O$ genes are involved in the response against pathogen attack. High accumulation of ST-ACO1 transcripts in potato was induced by PV A (Potato virus A) infection (Nie et al. 2002), and NA-ACO1 and NA-ACO3 in tobacco by TMV (Kim et al. 1998). In Nicotiana benthamiana leaves infected with the fungal pathogen, Colleotrichum orbiculare, highly increased levels of $\mathrm{NB}-\mathrm{ACO} 1$ were detected (Shan and Goodwin 2006). Similarly, an accumulation of $A C O$ gene transcripts has been noted in other pathogenic fungi-plant interactions (Chen et al. 2003; Lahey et al. 2004; Iwai et al. 2006). The studies on $N B$ $A C O 1$-silenced plants demonstrated that $A C O$ gene is not only inducible by a pathogenic attack but also plays an important role in the appearance of necrotrophy during the development of a fungal infection (Shan and Goodwin 2006).

\section{Transcriptional regulation of $A C O$ activity}

Although transcriptional regulation of $A C O$ in response to various developmental and environmental factors, has been studied extensively in many plant species, the knowledge on the corresponding transcriptional regulators is still scarce. The identification of transcription factors (TFs) specifically involved in $A C O$ gene activation or repression has proved difficult despite the presence of numerous putative cis-elements in the promoter sequences of $A C O$ genes (Lin et al. 2009). For example, the SL-ACO1 promoter contains ethylene-responsive elements (EREs), core motifs of TFs, such as GT-1 and Dofl that have been shown to be important for light-regulated genes, and putative homeobox protein-binding sites. These elements can be also found in promoter regions of several other $A C O \mathrm{~s}$, namely $D C-A C O, M E-A C O 3$, or $V R-A C O 1$.

Biochemical analysis showed that one of tomato ethylene responsive factors LeERF2/TERF2 interacted with GCC box in the promoter of NT-ACS3 and with dehydration-responsive element in the promoter of $\mathrm{LE}-\mathrm{ACO}$, resulting in transcriptional activation of the genes for ethylene biosynthesis in tomato and tobacco, which was suggested as a novel regulatory function of ERF proteins in plant ethylene biosynthesis (Zhang et al. 2009). The $5^{\prime}$ upstream region of $O S-A C O 1$ shown by Iwamoto et al. (2010) to have a promoter activity, also contains a GCCbox element (AGCCGCC) to which ERE-binding proteins/ factors (EREBPs/ERFs) may bind. Further, it has been shown that phytochrome-regulated EBL1 (OsEREBP1$L I K E 1)$ gene contributes to the regulation of $O S-A C O 1$ gene expression (Iwamoto and Takano 2011). Also Choudhury et al. (2008a, b) identified a GCC-box motif in the promoters of two $A C O$ homologs in banana and also found 
a $25-\mathrm{kDa}$ nuclear protein that was able to bind specifically to GCC-box DNA in the climacteric fruits. Furthermore, Huang et al. (2010) isolated two orthologs of EIN3 transcription factor which is necessary and sufficient for the activation of many ethylene-responsive genes in Arabidopsis (Solano et al. 1998) and demonstrated that they act as transcriptional activators of the $M C$ - $A C O 1$ gene in the melon ripening fruit.

Quite recently it has been reported that $A C O$ is transcriptionally regulated by a homeotic protein. Lin et al. (2008) identified a leucine zipper homeobox protein, LeHB-1, that transcriptionally modulates the expression of tomato $L E$-ACO1. The LeHB-1 protein contains 285 amino acid residues with a conserved homeodomain (HD) and a leucine zipper domain (Zip), belonging to the class-I HD-Zip proteins. In vitro gel retardation assays showed that LeHB-1 binds to the $L E-A C O 1$ promoter sequences that contain a $9 \mathrm{bp}$ AATA(A)TATT or 10 bp AATA(AA)TATT sequence with dyad symmetry and similarity to the putative homeobox protein-binding sites. Using virus-induced gene silencing (VIGS) to down-regulate LeHB-1 in tomato resulted in reduced expression of $L E-A C O 1 \mathrm{mRNA}$ and delayed ripening. These results indicated that LeHB-1 is a transcriptional activator that controls $L E-A C O 1$ expression in vivo (Lin et al. 2008).

In silico analysis of some $A C O$ gene promoters revealed the presence of TAAAATAT, which has been identified as a core element in LeCp (tomato Cys protease) binding ciselement of LeAcs 2 gene (Matarasso et al. 2005). LeCp has been characterized to be a dual-function protein, having enzymatic activity and, upon elicitor signaling, exhibiting transcriptional factor activity that induces LeAcs 2 expression. It can be hypothesized that it might act similarly as a regulator of $A C O$ genes.

\section{Altering ethylene levels in plants via ACO}

Genetic transformation is a powerful method for breeding crop plants with desired traits. Modifying the amount of ethylene produced under ripening, senescing, or stress conditions is the goal of a wide array of transgenic strategies (reviewed by Stearns and Glick 2003; Kępczyński and Kępczyńska 2005; Handa et al. 2010). Most of the research in this area has been directed toward the control of fruit ripening and flower senescence through genetic manipulation of the two key genes involved in ethylene biosynthesis, ACS and ACO. There are several examples of successful application of genetic engineering of $A C O$, which include tomato (Hamilton et al. 1990; Xiong et al. 2005), cantaloupe melon (Ayub et al. 1996), muskmelon (Nuñez-Palenius et al. 2006), or papaya (López-Gómez et al. 2009) fruits with longer shelf-life as well as carnation (Savin et al. 1995), torenia (Aida et al. 1998), and petunia
(Huang et al. 2007) flowers with increased longevity. The studies conducted by Huang et al. (2007) have even shown that using the antisense $B O-A C O 1$ gene from $B$. oleracea can be more effective than the antisense $B O-A C S 1$ gene in reducing ethylene biosynthesis and delaying flower senescence of $P$. hybrida.

First genetic engineering approaches worked out for ethylene manipulation through $A C O$ gene were based on the antisense gene technology (Hamilton et al. 1990). An introduction of the $A C O$ gene in antisense orientation has been proved as an efficient method for ethylene suppression and is still in use (Nuñez-Palenius et al. 2006; Kinouchi et al. 2006; Huang et al. 2007; Wang et al. 2009). Other studies have demonstrated that the introduction of truncated $A C O$ gene constructs in the sense orientation can result in co-suppression of homologous host genes, and modulate ethylene biosynthesis (Knoester et al. 1997; Aida et al. 1998; López-Gómez et al. 2009). The discovery of double-stranded RNA (dsRNA)-mediated gene silencing referred to as RNA interference (RNAi) has led to the development of new strategies to block gene function. For genetic improvement of crop plants, RNAi has advantages over antisense-mediated gene silencing and co-suppression, in terms of its efficiency, stability, and specificity. Transgenic tomato fruits with prolonged shelf life of more than 120 days have been produced by using RNAi technology (Xiong et al. 2005).

Regarding the transgenic strategies that face strong concern in public acceptance, new approaches for ethylene biosynthesis regulation through $A C O$ gene are worth mentioning. Over the past several years, consumer and environmental groups have expressed concerns regarding the use of antibiotic- and herbicide-resistance genes in ecological and food safety perspectives. A new transformation system overcoming such concerns has been established by Hao et al. (2011). A marker- and vector-free antisense $A C O$ construct was successfully transformed into melon via the pollen-tube pathway generating transgenic fruits with superior characteristics of greatly reduced respiration rates and endogenous ethylene production thus promising a significantly prolonged shelf-life compared to wild-type ones. A different strategy, totally avoiding plant transformation, was proposed by Dahmani-Mardas et al. (2010). They were also able to engineer melon plants with improved fruit shelf-life by means of targeting induced local lesions IN genome (TILLING) which combines advantages of random chemical mutagenesis and high throughput mutation discovery methods.

\section{Conclusions and perspectives}

Even though $A C O$ gene homologs have been isolated from a number of species, the biochemical properties, in vivo 
stability, and/or physiological functions of the gene products are in many cases not fully understood. Furthermore, it is often unclear whether a single gene is expressed in response to a variety of stimuli or a specific $A C O$ gene responds to a specific stimulus. Thus, further study is needed to verify the role played by different $A C O$ genes in the regulation of ethylene production. Different expression levels of $A C O$ genes induced by environmental and developmental signals, could explain function of identified isoforms in each species. Similarly important would be to reveal the structural organization of promoter regions of $A C O$ genes, as well as characterization of cis- and transacting regulatory elements. Better understanding of both structure and function of genes involved in ethylene biosynthesis, and also the mechanisms responsible for their activation or repression, make possible the regulation of their activity during different developmental processes of plants. All this has a profound practical importance as it develops the tools for crop and ornamental plants improvement.

Author contribution This review paper was accomplished with the collaboration of all authors under the supervision of Prof. J. Kępczyński. The research topic and framework were defined by J. Kępczyński who also revised the final version of the manuscript. The literature search and the first manuscript was written by M. Sasiak and J. Kępczyński. Further literature exploration and the manuscript revision was performed by I. Ruduś who was also responsible for the preparation of figures, revision of the table, checking the references and formatting the text. All authors have contributed their efforts to this work.

Open Access This article is distributed under the terms of the Creative Commons Attribution License which permits any use, distribution, and reproduction in any medium, provided the original author(s) and the source are credited.

\section{References}

Aida R, Yoshida T, Ichimura K, Goto R, Shibata M (1998) Extension of flower longevity in transgenic torenia plants incorporating ACC oxidase transgene. Plant Sci 138:91-101

Alexander L, Grierson D (2002) Ethylene biosynthesis and action in tomato: a model for climacteric fruit ripening. J Exp Bot 53: 2039-2055

Ayub R, Guis M, Ben Amor M, Guillot L, Roustan JP, Latché A, Bouzayen M, Pech JC (1996) Expression of ACC oxidase antisense gene inhibits ripening of cantaloupe melon fruits. Nat Biotechnol 14:862-866

Babula D, Misztal LH, Jakubowicz M, Kaczmarek M, Nowak M, Sadowski J (2006) Genes involved in biosynthesis and signalisation of ethylene in Brassica oleracea and Arabidopsis thaliana: identification and genome comparative mapping of specific gene homologues. Theor Appl Genet 112:410-420
Barry CS, Blume B, Bouzyen M, Cooper W, Hamilton AJ, Grierson D (1996) Differential expression of the 1-aminocyclopropane-1carboxylate oxidase gene family of tomato. Plant J 9:525-535

Binnie J, McManus MT (2009) Characterization of the 1-aminocyclopropane-1-carboxylic acid (ACC) oxidase multigene family of Malus domestica Borkh. Phytochemistry 70:348-360

Bui AQ, O'Neill SD (1998) Three 1-aminocyclopropane-1-carboxylate synthase genes regulated by primary and secondary pollination signals in orchid flowers. Plant Physiol 116:419-428

Calvo AP, Nicolas C, Lorenzo O, Nicolas G, Rodriguez D (2004) Evidence for positive regulation by gibberellins and ethylene of ACC oxidase expression and activity to germination in Fagus sylvatica L. seeds. J Plant Growth Regul 23:44-53

Chae HS, Cho YG, Park MY, Lee MC, Eun MY, Kang BG, Kim WT (2000) Hormonal cross-talk between auxin and ethylene differentially regulates the expression of two members of the 1-aminocyclopropane-1-carboxylate oxidase gene family in rice (Oryza sativa L.). Plant Cell Physiol 41:354-362

Chaves ALS, Mello-Farias PC (2006) Ethylene and fruit ripening: from illumination gas to the control of gene expression, more than a century of discoveries. Genet Mol Biol 29:508-515

Chen N, Goodwin PH, Hsiang T (2003) The role of ethylene during the infection of Nicotiana tabacum by Colletotrichum destructivum. J Exp Bot 54:2449-2456

Choudhury SR, Roy S, Saha PP, Singh SK, Sengupta DN (2008a) Characterization of differential ripening pattern in association with ethylene biosynthesis in the fruits of five naturally occurring banana cultivars and detection of a GCC-box-specific DNA-binding protein. Plant Cell Rep 27:1235-1249

Choudhury SR, Roy S, Sengupta DN (2008b) Characterization of transcriptional profiles of $M A-A C S 1$ and $M A-A C O 1$ genes in response to ethylene, auxin, wounding, cold and different photoperiods during ripening in banana fruit. J Plant Physiol 165:1865-1878

Chung MC, Chou SJ, Kuang LY, Charng Y, Yang SF (2002) Subcellular localization of 1-aminocyclopropane-1-carboxylic acid oxidase in apple fruit. Plant Cell Physiol 43:549-554

Costas M, Mehn MP, Jensen MP, Que L Jr (2004) Dioxygen activation at mononuclear nonheme iron active sites: enzymes, models, and intermediates. Chem Rev 104:939-986

Dahmani-Mardas F, Troadec C, Boualem A, Lévêque S, Alsadon AA, Aldoss AA, Digimont C, Bendahmane A (2010) Engineering melon plants with improved fruit shelf life using the TILLING approach. PLoS ONE 5(12):e15776. doi:10.1371/journal.pone. 0015776

Dereeper A, Guignon V, Blanc G, Audic S, Buffet S, Chevenet F, Dufayard J-F, Guindon S, Lefort V, Lescot M, Claverie J-M, Gascuel O (2008) Phylogeny.fr: robust phylogenetic analysis for the non-specialist. Nucleic Acids Res 1:36 (Web Server Issue): W465-W469

Dugardeyn J, Vandenbussche F, Van Der Straeten D (2008) To grow or not to grow: what can we learn on ethylene-gibberellin crosstalk by in silico gene expression analysis? J Exp Bot 59:1-16

Evans DE (2003) Aerenchyma formation. New Phytol 161:35-49

Fernández-Otero C, Matilla AJ, Rasori A, Ramina A, Bonghi C (2006) Regulation of ethylene biosynthesis in reproductive organs of damson plum (Prunus domestica L. subsp. Syriaca). Plant Sci 171:74-83

Gallie DR, Young TE (2004) The ethylene biosynthetic and perception machinery is differentially expressed during endosperm and embryo development in maize. Mol Genet Genomics 271:267-281

Gallie DR, Geisler-Lee J, Chen J, Jolley B (2009) Tissue-specific expression of the ethylene biosynthetic machinery regulates root growth in maize. Plant Mol Biol 69:195-211 
Gómez-Lim MA, Valdez-Lopez V, Cruz-Hernandez A, Saucedo-Arias LJ (1993) Isolation and characterization of gene involved in ethylene biosynthesis in Arabidopsis thaliana. Gene 134:217-221

Hamilton AJ, Lycett GW, Grierson D (1990) Antisense gene that inhibits synthesis of the hormone ethylene in transgenic plants. Nature 346:284-287

Handa AK, Srivastava A, Deng Z, Gaffe J, Arora A, TiznadoHernández ME, Goyal RK, Malladi A, Negi PS, Mattoo AK (2010) Biotechnological interventions to improve plant developmental traits. In: Kole C, Michler C, Abbott AG, Hall TC (eds) Transgenic crop plants, 1st edn. Springer, Berlin, pp 199-248

Hao JF, Niu YD, Yang BJ, Gao F, Zhang LQ, Wang J, Hasi A (2011) Transformation of a marker-free and vector-free antisense ACC oxidase gene cassette into melon via the pollen-tube pathway. Biotechnol Lett 33:55-61

Hermann K, Meinhard J, Dobrev P, Linkies A, Pesek B, Heß B, Macháčková I, Fischer U, Leubner-Metzger G (2007) 1-Aminocyclopropane-1-carboxylic acid and abscisic acid during the germination of sugar beet (Beta vulgaris L.): a comparative study of fruits and seeds. J Exp Bot 58:3047-3060

Holdsworth MJ, Schuch W, Grierson D (1987) Nucleotide sequence of an ethylene-related gene from tomato. Nucleic Acids Res $15: 10600$

Huang LC, Lai UL, Yang SF, Chua MJ, Kuo CI, Tsai MF, Sun CW (2007) Delayed flower senescence of Petunia hybrida plants transformed with antisense broccoli ACC synthase and ACC oxidase genes. Postharvest Biol Technol 46:47-53

Huang S, Sawaki T, Takahashi A, Mizuno S, Takezawa K, Matsumura A, Yokotsuka M, Hirasawa Y, Sonoda M, Nakagawa $\mathrm{H}$, Sato $\mathrm{T}$ (2010) Melon EIN3-like transcription factors (CmEIL1 and CmEIL2) are positive regulators of an ethyleneand ripening-induced 1-aminocyclopropane-1-carboxylic acid oxidase gene (CM-ACO1). Plant Sci 178:251-257

Hunter DA, Yoo SD, Butcher SM, McManus MT (1999) Expression of 1-aminocyclopropane-1-carboxylate oxidase during leaf ontogeny in white clover. Plant Physiol 120:131-141

Iglesias-Fernández R, Matilla A (2009) After-ripening alters the gene expression pattern of oxidases involved in the ethylene and gibberellin pathways during early imbibition of Sisymbrium officinale L. seeds. J Exp Bot 60:1645-1661

Iglesias-Fernández R, Matilla A (2010) Genes involved in ethylene and gibberellins metabolism are required for endosperm-limited germination of Sisymbrium officinale L. seeds. Germination in Sisymbrium officinale L. seeds. Planta 231:653-664

Inaba A, Liu X, Yokotani N, Yamane M, Lu WJ, Nakano R, Kubo Y (2007) Differential feedback regulation of ethylene biosynthesis in pulp and peel tissues of banana fruit. J Exp Bot 58:1047-1057

Iwai T, Miyasaka A, Seo S, Ohashi Y (2006) Contribution of ethylene biosynthesis for resistance to blast fungus infection in young rice plants. Plant Physiol 142:1202-1215

Iwamoto M, Takano M (2011) Phytochrome-regulated EBL1 contributes to ACO1 upregulation in rice. Biotechnol Lett 33: 173-178

Iwamoto M, Baba-Kasai A, Kiyota S, Hara N, Takano M (2010) ACO1, a gene for aminocyclopropane-1-carboxylate oxidase: effects on internode elongation at the heading stage in rice. Plant, Cell Environ 33:805-815

Iwamoto M, Kiyota S, Hanada A, Yamaguchi S, Takano M (2011) The multiple contributions of phytochromes to the control of internode elongation in rice. Plant Physiol 157:1187-1195

Jones ML (2003) Ethylene biosynthetic genes are differentially regulated by ethylene and ACC in carnation styles. Plant Growth Regul 40:129-138

Jones ML, Woodson WR (1997) Pollination-induced ethylene in carnation (role of stylar ethylene in corolla senescence). Plant Physiol 115:205-212
Kende H (1993) Ethylene biosynthesis. Annu Rev Plant Physiol Plant Mol Biol 44:283-307

Kępczyński J, Kępczyńska E (1997) Ethylene in seed dormancy and germination. Physiol Plant 101:120-126

Kępczyński J, Kępczyńska E (2005) Manipulation of ethylene biosynthesis. Acta Physiol Plant 27:213-220

Kim WT, Yang SF (1994) Structure and expression of cDNAs encoding 1-aminocyclopropane-1-carboxylate oxidase homologs isolated from excised mung bean hypocotyls. Planta 194:223-229

Kim YS, Choi D, Lee MM, Lee SH, Kim WT (1998) Biotic and abiotic stress-related expression of 1-aminocyclopropane-1carboxylate oxidase gene family in Nicotiana glutinosa L. Plant Cell Physiol 39:565-573

Kinouchi T, Endo R, Yamashita A, Satoh S (2006) Transformation of carnation with genes related to ethylene production and perception: towards generation of potted carnations with a longer display time. Plant Cell Tissue Organ 86:27-35

Knoester M, Linthorst HJM, Bol JF, van Loon LC (1997) Modulation of stress-inducible ethylene biosynthesis by sense and antisense gene expression in tobacco. Plant Sci 126:173-183

Köck M, Hamilton A, Grierson D (1991) ethl, a gene involved in ethylene synthesis in tomato. Plant Mol Biol 17:141-142

Lahey KA, Yuan RC, Burns JK, Ueng PP, Timmer LW, Chung KR (2004) Induction of phytohormones and differential gene expression in citrus flowers infected by the fungus Colletotrichum acutatum. Mol Plant Microbe Interact 17:1394-1401

Lasserre E, Bouquin T, Hernandez JA, Bull J, Pech JC, Balagu C (1996) Structure and expression of three genes encoding ACC oxidase homologs from melon (Cucumis melo L.). Mol Gen Genet 251:81-90

Lin Z, Hong Y, Yin M, Li C, Zhang K, Grierson D (2008) A tomato HD-Zip homeobox protein, LeHB-1, plays an important role in floral organogenesis and ripening. Plant J 55:301-310

Lin Z, Zhong S, Grierson D (2009) Recent advances in ethylene research. J Exp Bot 60:3311-3336

Linkies A, Leubner-Metzger G (2012) Beyond gibberellins and abscisic acid: how ethylene and jasmonates control seed germination. Plant Cell Rep 31:253-270

Linkies A, Müller K, Morris K, Turečková V, Wenk M, Cadman CSC, Corbineau F, Strnad M, Lynn JR, Finch-Savage WE, Leubner-Metzger G (2009) Ethylene interacts with abscisic acid to regulate endosperm rupture during germination: a comparative approach using Lepidium sativum and Arabidopsis thaliana. Plant Cell 21:3803-3822

Liu JH, Lee-Tamon SH, Reid DM (1997) Differential and woundinducible expression of 1-aminocyclopropane-1-carboxylate oxidase genes in sunflower seedlings. Plant Mol Biol 34:923-933

López-Gómez R, Cabrera-Ponce JL, Saucedo-Arias LJ, CarretoMontoya L, Villanueva-Arce R, Díaz-Perez JC, Gómez-Lim MA, Herrera-Estrella L (2009) Ripening in papaya fruit is altered by ACC oxidase cosuppression. Transgenic Res 18: 89-97

Matarasso N, Schuster S, Avni A (2005) A novel plant cysteine protease has a dual function as a regulator of 1-aminocyclopropane-1-carboxylic acid synthase gene expression. Plant Cell $17: 1205-1216$

Mathooko FM, Tsunashima Y, Kubo Y, Inaba A (2004) Expression of a 1-aminocyclopropane-1-carboxylate (ACC) oxidase gene in peach (Prunus persica L.) fruit in response to treatment with carbon dioxide and 1-methylcyclopropene: possible role of ethylene. Afr J Biotechnol 3:497-502

Matilla AJ, Matilla-Vázquez MA (2008) Involvement of ethylene in seed physiology. Plant Sci 175:87-97

Mekhedov SL, Kende H (1996) Submergence enhances expression of a gene encoding 1-aminocyclopropane-1-carboxylate oxidase in deepwater rice. Plant Cell Physiol 37:531-537 
Mirica LM, Klinman PJ (2008) The nature of $\mathrm{O}_{2}$ activation by the ethylene-forming enzyme 1-aminocyclopropane-1-carboxylic acid oxidase. PNAS 12:1814-1819

Moeder W, Barry CS, Tauriainen AA, Betz C, Tuomainen J, Utriainen M, Grierson D, Sandermann H, Langebartels C, Kangasjärvi J (2002) Ethylene synthesis regulated by biphasic induction of 1-aminocyclopropane-1-carboxylic acid synthase and 1-aminocyclopropane-1-carboxylic acid oxidase genes is required for hydrogen peroxide accumulation and cell death in ozone-exposed tomato. Plant Physiol 130:1918-1926

Momonoi K, Shoji K, Yoshida K (2007) Cloning and characterization of ACC oxidase genes from tulip. Plant Biotechnol 24:241-246

Munoz De Rueda P, Gallardo M, Matilla AJ, Sanchez-Calle IM (1995) Preliminary characterization of 1-aminocyclopropane1-carboxylate oxidase properties from embryonic axes of chickpea (Cicer arietinum L.) seeds. J Exp Bot 46:695-700

Nakatsuka A, Murachi S, Okunishi H, Shiomi S, Nakano R, Kubo Y, Inaba A (1998) Differential expression and internal feedback regulation of 1-aminocyclopropane-1-carboxylate synthase, 1-aminocyclopropane-1-carboxylate oxidase, and ethylene receptor genes in tomato fruit during development and ripening. Plant Physiol 118:1295-1305

Nie X, Singh RP, Tai GCC (2002) Molecular characterization and expression analysis of 1-aminocyclopropane-1-carboxylate oxidase homologs from potato under abiotic and biotic stresses. Genome 45:905-913

Nuñez-Palenius HG, Cantliffe DJ, Huber DJ, Ciardi J, Klee HJ (2006) Transformation of a muskmelon 'Galia' hybrid parental line (Cucumis melo L. var. reticulatus Ser.) with an antisense ACC oxidase gene. Plant Cell Rep 25:198-205

O'Neill SD, Nadeau JA, Zhang XS, Bui AQ, Halevy AH (1993) Interorgan regulation of ethylene biosynthetic genes by pollination. Plant Cell 5:419-432

Ouyang S, Zhu W, Hamilton J, Lin H, Campbell M, Childs K, Thibaud-Nissen F, Malek RL, Lee Y, Zheng L, Orvis J, Haas B, Wortman J, Buell CR (2007) The TIGR rice genome annotation resource: improvements and new features. Nucleic Acids Res 35:D883-D887

Owino WO, Manabe Y, Mathooko FM, Kubo Y, Inaba A (2006) Regulatory mechanisms of ethylene biosynthesis in response to various stimuli during maturation and ripening in fig fruit (Ficus carica L.). Plant Physiol Biochem 44:335-342

Pan G, Lou CF (2008) Isolation of an 1-aminocyclopropane-1carboxylate oxidase gene from mulberry (Morus alba L.) and analysis of the function of this gene in plant development and stresses response. J Plant Physiol 165:1204-1213

Pech JC, Latché A, Bouzayen M (2010) Ethylene biosynthesis. In: Davies PJ (ed) Plant hormones: biosynthesis, transduction, action, 3rd edn. Springer, Dordrecht, pp 115-136

Pereira LFP, Galvao RM, Kobayashi AK, Cacao SMB, Vieira LGE (2005) Ethylene production and acc oxidase gene expression during fruit ripening of Coffea arabica L. Braz J Plant Physiol 17:283-289

Petruzzelli L, Coraggio I, Leubner-Metzger G (2000) Ethylene promotes ethylene biosynthesis during pea seed germination by positive feedback regulation of 1-aminocyclopropane-1-carboxylic acid oxidase. Planta 211:144-149

Punta M, Coggill PC, Eberhardt RY, Mistry J, Tate J, Boursnell C, Pang N, Forslund K, Ceric G, Clements J, Heger A, Holm L, Sonnhammer ELL, Eddy SR, Bateman A, Finn RD (2012) The Pfam protein families database. Nucleic Acids Res 40(D1): D290-D301

Raghavan C, Ong EK, Dalling MJ, Stevenson TW (2006) Regulation of genes associated with auxin, ethylene and ABA pathways by 2,4-dichlorophenoxyacetic acid in Arabidopsis. Funct Integr Genomics 6:60-70
Ramassamy S, Olmos E, Bouzayen M, Pech JC, Latché A (1998) 1-Aminocyclopropane-1-carboxylate oxidase of apple fruit is periplasmic. J Exp Bot 49:1909-1915

Ramonell KM, McClure G, Musgrave ME (2002) Oxygen control of ethylene biosynthesis during seed development in Arabidopsis thaliana (L.) Heynh. Plant, Cell Environ 25:793-801

Raz V, Ecker JR (1999) Regulation of differential growth in the apical hook of Arabidopsis. Development 126:3661-3668

Rodríguez-Gacio MC, Nicolás C, Matilla AJ (2004) The final step of the ethylene biosynthesis pathway in turnip tops (Brassica rapa): molecular characterization of the 1-aminocyclopropane-1-carboxylate oxidase $\mathrm{BrACO1}$ throughout zygotic embryogenesis and germination of heterogeneous seeds. Physiol Plant 121: $132-140$

Roeder S, Dreschler K, Wirtz M, Cristescu SM, van Harren FJM, Hell R, Piechulla B (2009) SAM levels, gene expression of SAM synthetase, methionine synthase and ACC oxidase, and ethylene emission from N. suaveolens flowers. Plant Mol Biol 70:535546

Ruperti B, Bonghi C, Rasori A, Ramina A, Tonutti P (2001) Characterization and expression of two members of the peach 1-aminocyclopropane-1-carboxylate oxidase gene family. Physiol Plant 111:336-344

Savin KW, Baudinette SC, Graham MW, Michael MZ, Nugent GD, Lu CY, Chandler SF, Cornish ED (1995) Antisense ACC oxidase RNA delays carnation petal senescence. HortScience 30:970-972

Sell S, Hehl R (2005) A fifth member of the tomato 1-aminocyclopropane-1-carboxylic acid (ACC) oxidase gene family harbours a leucine zipper and is anaerobically induced. DNA Seq 16:80-82

Shan XC, Goodwin PH (2006) Silencing an ACC oxidase gene affects the susceptible host response of Nicotiana benthamiana to infection by Colletotrichum orbiculare. Plant Cell Rep 25: 241-247

Solano R, Stepanova A, Chao Q, Ecker JR (1998) Nuclear events in ethylene signaling: a transcriptional cascade mediated by ethylene-insensitive3 and ethylene-response-factor1. Gene Dev 12:3703-3714

Stearns JC, Glick BR (2003) Transgenic plants with altered ethylene biosynthesis or perception. Biotechnol Adv 21:193-210

Takahashi H, Shinkawa T, Nakai S, Inoue Y (2010) Differential expression of ACC oxidase genes during low-pH-induced root hair formation in lettuce (Lactuca sativa L.) seedlings. Plant Growth Regul 62:137-149

Tang X, Woodson WR (1996) Temporal and spatial expression of 1-aminocyclopropane-1-carboxylate oxidase mRNA following pollination of immature and mature petunia flowers. Plant Physiol 112:503-511

Tang X, Wang H, Brandt AS, Woodson WR (1993) Organization and structure of the 1-aminocyclopropane-1-carboxylate oxidase gene family from Petunia hybrida. Plant Mol Biol 23:1151-1164

Trivellini A, Ferrante A, Vernieri P, Serra G (2011) Effects of abscisic acid on ethylene biosynthesis and perception in Hibiscus rosa-sinensis L. flower development. J Exp Bot 62:5437-5452

Vandenbussche F, Vaseva I, Vissenberg K, Van Der Straeten D (2012) Ethylene in vegetative development: a tale with a riddle. New Phytol. doi:10.1111/j.1469-8137.2012.04100.x

Vriezen WH, Hulzink R, Mariani C, Voesenek LACJ (1999) 1-Aminocyclopropane-1-carboxylate oxidase activity limits ethylene biosynthesis in Rumex palustris during submergence. Plant Physiol 121:189-195

Wagstaff C, Chanasut U, Harren FJM, Laarhoven LJ, Thomas B, Rogers HJ, Stead AD (2005) Ethylene and flower longevity in Alstroemeria: relationship between tepal senescence, abscission and ethylene biosynthesis. J Exp Bot 56:1007-1016 
Wang TW, Arteca RN (1992) Effects of low $\mathrm{O}_{2}$ root stress on ethylene biosynthesis in tomato plants (Lycopersicon esculentum Mill cv. Heinz 1350). Plant Physiol 98:97-100

Wang KLC, Li H, Ecker JR (2002) Ethylene biosynthesis and signaling networks. Plant Cell 14(Suppl):S131-S151

Wang AQ, Dong WQ, Wei YW, Huang CM, He LF, Yang LT, Li YR (2009) Transformation of sugarcane with ACC oxidase antisense gene. Sugar Tech 11:39-43

Wilkinson JQ, Lanahan MB, Clark DG, Bleecker AB, Chang C, Meyerowitz EM, Klee HJ (1997) A dominant mutant receptor from Arabidopsis confers ethylene insensitivity in heterologous plants. Nat Biotechnol 15:444-447

Xiong AS, Yao QH, Peng RH, Li X, Han PL, Fan HQ (2005) Different effects on ACC oxidase gene silencing triggered by RNA interference in transgenic tomato. Plant Cell Rep 23: 639-646

Yang SF, Hoffman NE (1984) Ethylene biosynthesis and its regulation in higher plants. Annu Rev Plant Physiol 35:155-189
Yoo A, Seo YS, Jung JW, Sung SK, Kim WT, Lee WT, Yang DR (2006) Lys296 and Arg299 residues in the C-terminus of MDACO1 are essential for a 1-aminocyclopropane-1-carboxylate oxidase enzyme activity. J Struct Biol 156:407-420

Yuan S, Wang Y, Dean JFD (2010) ACC oxidase genes expressed in the wood-forming tissues of loblolly pine (Pinus taeda L.) include a pair of nearly identical paralogs (NIPs). Gene 453:24-36

Zhang Z, Zhang H, Quan R, Wang XC, Huang R (2009) Transcriptional regulation of the ethylene response factor LeERF2 in the expression of ethylene biosynthesis genes controls ethylene production in tomato and tobacco. Plant Physiol 150:365-377

Zhao Y, Hasenstein KH (2009) Primary root growth regulation: the role of auxin and ethylene antagonists. J Plant Growth Regul 28:309-320

Zhou Z, Vriezen W, Caeneghem W, Van Montagu M, Van Der Straeten D (2001) Rapid induction of a novel ACC synthase gene in deepwater rice seedlings upon complete submergence. Euphytica 121:137-143 